\title{
Sex differences in reported and objectively measured sleep in COPD
}

\author{
This article was published in the following Dove Press journal: \\ International Journal of COPD \\ 25 January 2016 \\ Number of times this article has been viewed
}

\author{
Jenny Theorell-Haglöw' \\ Inga Sif Ólafsdóttir ${ }^{1-3}$ \\ Bryndís Benediktsdóttir ${ }^{2,3}$ \\ Thórarinn Gíslason ${ }^{2,3}$ \\ Eva Lindberg' \\ Christer Janson' \\ 'Department of Medical Sciences, \\ Respiratory, Allergy and Sleep \\ Research, Uppsala University, Uppsala, \\ Sweden; ${ }^{2}$ Department of Respiratory \\ Medicine and Sleep, Landspitali \\ University Hospital, ${ }^{3}$ Medical Faculty, \\ University of Iceland, Reykjavík, \\ Iceland
}

Background: The aim was to assess and compare reported sleep disturbances and objectively measured sleep in men and women with COPD compared with controls and also explore sex differences.

Methods: A total of 96 patients with COPD and 90 age- and sex-matched controls answered a sleep questionnaire, underwent ambulatory polysomnography, a post-bronchodilatory spirometry, and blood sampling.

Results: Of the patients with COPD, 51\% reported sleep disturbances as compared with 31\% in controls $(P=0.008)$. Sleep disturbances were significantly more prevalent in males with COPD compared with controls, whereas there was no significant difference in females. The use of hypnotics was more common among patients with COPD compared with controls, both in men $(15 \%$ vs $0 \%, P=0.009)$ and women $(36 \%$ vs $16 \%, P=0.03)$. The men with COPD had significantly longer recorded sleep latency than the male control group (23 vs 9.3 minutes, $P<0.001$ ), while no corresponding difference was found in women. In men with COPD, those with reported sleep disturbances had lower forced vital capacity, higher C-reactive protein, myeloperoxidase, and higher prevalence of chronic bronchitis.

Conclusion: The COPD was associated with impaired sleep in men while the association was less clear in women. This was also confirmed by recorded longer sleep latency in male subjects with COPD compared with controls.

Keywords: chronic obstructive pulmonary disease, sleep, polysomnography, quality of sleep, sex

\section{Background}

The COPD is characterized by a poorly reversible airflow limitation resulting from chronic inflammation, primarily due to smoking exposure, and resulting in multiple extra pulmonary comorbidities. The patients with COPD often report sleep disturbances and studies have indicated patients with COPD as having more difficulty falling, maintaining, and staying asleep, and also having more daytime sleepiness. ${ }^{1,2}$ In two large studies, approximately $40 \%$ of the patients with COPD reported sleep disturbances, ${ }^{3,4}$ and there are also studies reporting a higher prevalence of insomnia, nightmares, and daytime sleepiness in this group. ${ }^{5}$ In addition, they also have a higher regular use of hypnotics. ${ }^{2,6}$ Restless legs syndrome which is frequently associated with insomnia is also more frequent among patients with COPD. ${ }^{7}$

Furthermore, nighttime dyspnea is prevalent in patients with COPD, and can impair and disrupt sleep and result in tiredness. ${ }^{8}$ Hypoventilation during sleep is more pronounced in patients with COPD due to factors such as air flow obstruction, hyperinflation, respiratory muscle dysfunction, decreased ventilatory response to hypercapnia, and/or hypoxia but also due to medications. ${ }^{9}$ Sleep-related disturbances in gas exchange are considered a consequence of the disease itself and being separate and distinct from that of sleep-disordered breathing ${ }^{10}$ and there is also no indication
Correspondence: Jenny Theorell-Haglöw Department of Medical Sciences, Respiratory, Allergy and Sleep Research, Uppsala University, Akademiska sjukhuset, Ing 40, 2 tr, SE-75I 85 Uppsala, Sweden

Tel +46186110242

$\mathrm{Fax}+46$ I8 6II 0228

Email jenny.theorell-haglow@medsci.

uu.se 
that obstructive sleep apnea is more common among patients with COPD than in the general population. ${ }^{4}$

Most studies on COPD and sleep, using objective measures have aimed to study the effects on nighttime saturation and not sleep architecture, ${ }^{11}$ although some small studies investigating sleep in COPD with objective measures indicate higher prevalence of light non-rapid eye movement (REM) sleep stages and more fragmented sleep. ${ }^{12}$ In 16 patients with COPD investigated by Cormick et al, the patients displayed more sleep fragmentation, diminished slow wave, and REM sleep, ${ }^{2}$ and Fleetham et al showed shorter sleep duration and more sleep fragmentation in COPD than healthy controls. ${ }^{13}$ Earlier studies indicate that there are sex differences both for subjective and objective sleep showing that women have more subjective sleep complaints although objectively measured sleep does not reflect this. Studies have also shown that women have increased slow-wave sleep (SWS) as compared with men at any given age. ${ }^{14}$ However, to our knowledge, there are no earlier studies investigating sex differences in COPD.

Therefore, the aim of this study was to assess and compare reported sleep disturbances and objectively measure sleep using polysomnography in a large group of subjects (men and women) with and without COPD. In addition, the aim was to explore factors (including inflammatory markers) related to reported sleep disturbances and objectively measure sleep and also to explore sex differences. We hypothesized that both subjective and objective sleep would be worse in patients with COPD. In addition, we hypothesized that poor sleep would be associated with increased inflammation and that there would be sex differences.

\section{Patients and methods}

In this case-control study, 100 patients with COPD (men and women) and 100 sex- and age-matched control subjects were recruited. The male and female patients with COPD came from respiratory outpatient clinics at the Uppsala University Hospital, Uppsala; or General Practitioner clinics in Uppsala, Sweden. Female controls were recruited from an ongoing population-based study of women, ${ }^{15}$ whereas healthy males were recruited from another population-based study. ${ }^{16}$ Inclusion criteria for the patients were: 1) doctors diagnosed COPD (International Classification of Diseases 10: J44); 2) forced expiratory volume in 1 second/forced vital capacity $\left(\mathrm{FEV}_{1} / \mathrm{FVC}\right.$ ) ratio $<70 \%$ after bronchodilation (with $400 \mu \mathrm{g}$ salbutamol); 3) stable disease with no exacerbations in the last 4 weeks; and 4) a wish to participate in the study. The patients not able to undergo whole-night polysomnography in their own home, receiving supplemental oxygen, or on oral steroid treatment were excluded. Inclusion criteria for the controls were: 1) no reported diagnosed COPD; 2) $\mathrm{FEV}_{1} /$ FVC ratio $\geq 70 \%$; and 3 ) a wish to participate in the study.

The data were gathered over 2 consecutive days. On the first day, subjects performed a spirometry both before and after bronchodilation, for securing or excluding the diagnosis and COPD. Spirometry confirmed the COPD diagnosis in 96 patients with COPD and excluded COPD in 90 of the controls. Following the spirometry subjects underwent anthropometric measurements, structured interviews, and answered questionnaires, they also received instructions regarding the ambulatory polysomnography and were fitted with polysomnography equipment. On the second day, the subjects returned with polysomnographic equipment, venous blood was sampled, and subjects answered a questionnaire on sleep and bronchodilatory use during the preceding night. Figure 1 shows a flow chart of the study.

Prior to the polysomnography, the participants filled in questionnaires, including questions on sleep-related issues and symptoms, somatic disease, medication and also questions on snoring, daytime sleepiness, physical activity, and tobacco use.

Subjective sleep disturbances were assessed using the question: "Do you have problems with your sleep?" with a "yes" or "no" answer, where answering "Yes" was considered indicating sleep disturbances. The sleep questionnaire also included questions on snoring, nocturnal reflux, nocturnal body movements, and nocturia. The questionnaire also evaluated subjective daytime symptoms such as not feeling rested in the morning, daytime sleepiness, and daytime fatigue. All answers were indicated on a five-point scale: 1 (never); 2 (seldom); 3 (sometimes); 4 (often); and 5 (very often). ${ }^{17,18}$ The participants scoring 3 to 5 on these questions were defined as an indication to the symptom. Furthermore, symptoms of restless leg syndrome were assessed by four questions on 1) desire to move the extremities; 2) motor restlessness; 3) worsening of symptoms at rest with at least temporary relief by activity; and 4) worsening of symptoms in the evening or night. Answering "yes" to two or more of the questions indicated symptoms of restless legs. ${ }^{19}$ The participants were also asked to state the use of hypnotics.

Symptoms of insomnia were assessed by three questions, one on difficulties initiating sleep (DIS); one on difficulty maintaining sleep, and one on early morning awakening. ${ }^{18,20}$ As in the questions on daytime symptoms, the participants rated their difficulties on a five-point scale where 1 indicated "no problems" and 5 meant "very severe problems". The participants were considered to have the symptom if scoring 3-5. 
Spirometry after inhaling
$400 \mu \mathrm{g}$ salbutamol

Ambulatory full night polysomnography (PSG)

Final study population
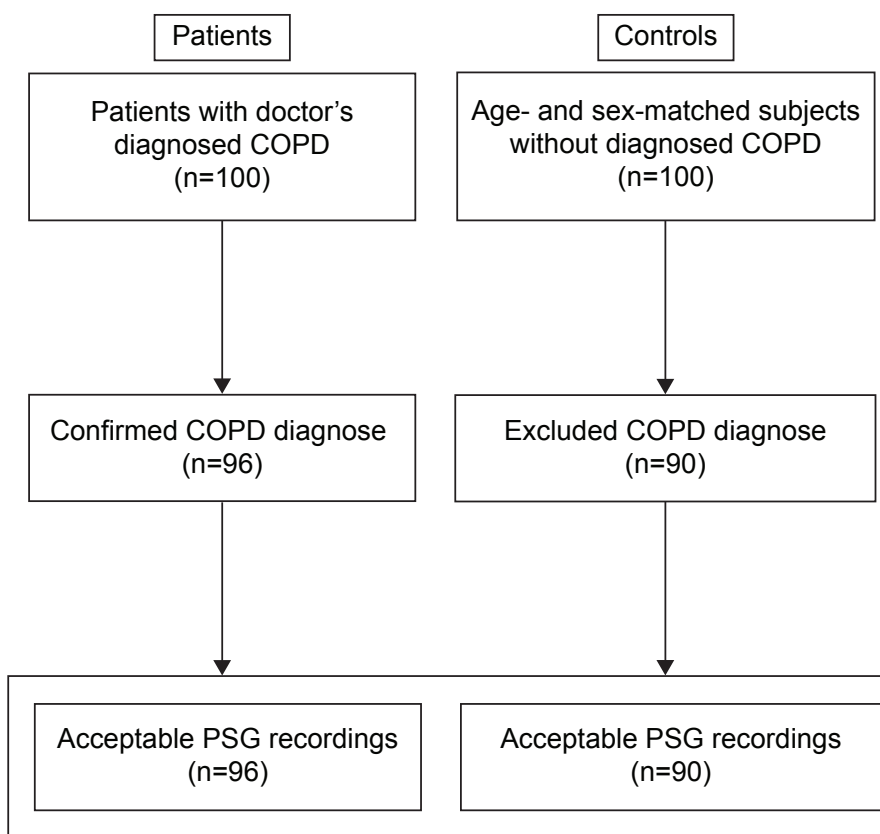
$(n=90)$
Acceptable PSG recordings

Figure I Flowchart of the study.

Health-related quality of life was evaluated in the patients using the St George Respiratory Questionnaire (SGRQ). ${ }^{21}$ The SGRQ is a disease-specific instrument designed to measure impact on overall health, daily life, and perceived well-being in patients with obstructive airway disease. The instrument includes three components; one symptom component (frequency and severity), one component on activities that cause or are limited by breathlessness, and one component on impact on social functioning, psychological disturbances resulting from airways disease. Scores range from 0 to 100, with higher scores indicating more limitations.

Anxiety and depressive status were assessed in the patients with COPD using the Hospital Anxiety and Depression scale. ${ }^{22}$ This is a self-administered rating scale that was originally designed for the patients with physical illness. ${ }^{22}$ It is well-validated and has often been used in studies to identify the levels of anxiety and depression. ${ }^{23-25}$ The questionnaire consists of 14 questions with seven concerning anxiety and seven concerning depression. All questions are scored from 0 to 3 , yielding a maximum of 21 points for the anxiety scale and 21 points for the depression scale.

The participants answered questionnaires regarding respiratory and bronchitis symptoms and medication intake, using the questionnaires used in the European Community Respiratory Health Survey ${ }^{26}$ Dyspnea severities were graded according to the Medical Research Council scale. ${ }^{27}$ Chronic bronchitis was defined as reporting having chronic phlegm at least 3 months per year in 2 consecutive years. The questionnaires also included a question on somatic disease where the participants were asked if they had any somatic disease(s) that required regular medical attention. ${ }^{18}$

Six questions assessed smoking habits. ${ }^{28}$ Based on the participants' responses they were categorized as "current smokers" or "nonsmokers" (ie, never smoked or had quit smoking at least 6 months before answering the questionnaire).

\section{Spirometry}

Pre-bronchodilator spirometry was performed according to American Thoracic Society Standards using a Welch Allyn spirometer (Welch Allyn Ltd, Skaneateles Falls, NY, USA) and repeated 15 minutes after inhalation of $400 \mu \mathrm{g}$ salbutamol via large-volume spacer. The best of three readings for both $\mathrm{FEV}_{1}$ and $\mathrm{FVC}$ was recorded, and expressed in liters and percentage of predicted normal using the European Community Coal and Steel data set. ${ }^{29}$

\section{Polysomnography}

The participants received instructions and had electrodes for polysomnography attached to the research facility to perform a whole-night polysomnography in their own home. Polysomnography was performed by using the ambulatory system EMBLA (Flaga Inc., Reykjavík, Iceland). A total of 16 channels were recorded and included two electro-encephalography leads (C3-A2 and C4-A1), two electrooculography leads, and three electromyography leads (submental, and left and right anterior tibialis muscles). In addition, two airflow leads (oronasal 
thermistor and nasal flow pressure sensor), one pharyngeal sound lead (piezo vibration sensor), and two respiratory effort leads (thoracic and abdominal piezo crystal transducers) were included. Furthermore, one oximeter lead (to measure oxygen saturation level and pulse from a finger probe), two electrocardiography leads, and one body position lead were included. The data were downloaded to the Somnologica reviewing analysis software (Version 2.0; Flaga Inc., Reykjavík, Iceland) and sleep was scored manually in 30-second epochs according to standard criteria. ${ }^{30}$ The polysomnography was considered acceptable when $\geq 4$ hours of sleep were recorded and no registration had been lost for $\geq 20$ minutes of the night.

The sleep-associated variables included total sleep time (TST), SWS (Stage 3; in minutes and as \% of total sleep duration), Stage 1 and 2 sleep (in minutes and as \% of total sleep duration), REM sleep (in minutes and as \% of total sleep duration), sleep latency (SL), number of awakenings, apnea-hypopnea index (AHI; the average number of apneas and hypopneas/hour of sleep; apnea: complete cessation of nasal and oral airflow lasting $\geq 10$ seconds; hypopnea: $\geq 50 \%$ reduction in airflow amplitude compared to baseline, in combination with a reduction $\geq 3 \%$ in oxyhemoglobin saturation, or an arousal), oxygen desaturation index (ODI; total desaturations $\geq 4 \%$ /hour of sleep), and lowest oxygen saturation during the night.

\section{Blood sampling and anthropometric variables}

Blood sampling was used to measure: highly sensitive C-reactive protein (CRP), Interleukin-6 (IL-6), myeloperoxidase (MPO), and Type B natriuretic protein, all in serum. The anthropometric variables height and weight were measured by a research nurse and body mass index (BMI) was calculated as weight $(\mathrm{kg}) /$ height $^{2}\left(\mathrm{~m}^{2}\right)$. Blood pressure was measured in the right arm after 15-minute rest in a supine position.

\section{Statistical analyses}

Statistical analyses were performed using Stata 10 and Stata 13 (StataCorp., College Station, TX, USA). Univariate analyses were conducted using the unpaired Student's $t$-test or the chi-squared test to compare baseline data between groups. Associations between COPD and sleep were further analyzed using multiple linear regression analysis. Interaction analyses were conducted to detect significant differences in the associations between sex and sleep. From this analysis, significant difference in the association between sex and sleep was detected, and therefore, all analyses were stratified by sex. A $P$-value $<0.05$ was considered indicating a significant difference.

The study was approved by the Ethics Committee of the Medical Faculty at Uppsala University, and all participants in the study gave their written informed consent.

\section{Results}

Of all the patients with COPD, 51\% reported having sleep disturbances compared to $31 \%$ of the controls $(P=0.008)$. Both in patients with COPD and in controls sleep disturbances were more common among females than males. However, when stratifying by sex a statistically significant difference between patients with COPD and controls was found in men but not in women (Figure 2).

Females with COPD had a lower BMI than control females, while there was no difference in BMI among male patients with COPD and controls. Both men and women with COPD were more often smokers or ex-smokers, and they also had lower $\mathrm{FEV}_{1}, \mathrm{FVC}$, and daytime oxygen saturation $\left(\mathrm{SaO}_{\text {2awake }}\right)$ compared with controls. In addition, both male and female patients with COPD had higher levels of IL-6, and in male patients with COPD, CRP was also significantly increased. Sleep disturbances were significantly more prevalent in men with COPD compared with controls whereas there was no significant difference in women (Table 1).

Men with COPD significantly more often reported problems with nocturnal body movement and DIS compared with controls; results not seen in women. In both men and women, the use of hypnotics was more frequent among the patients with COPD compared with controls (Table 2).

Among the controls, females more often reported not feeling rested in the morning, daytime sleepiness, and daytime fatigue compared with males. However, when comparing patients with COPD to controls, these symptoms were

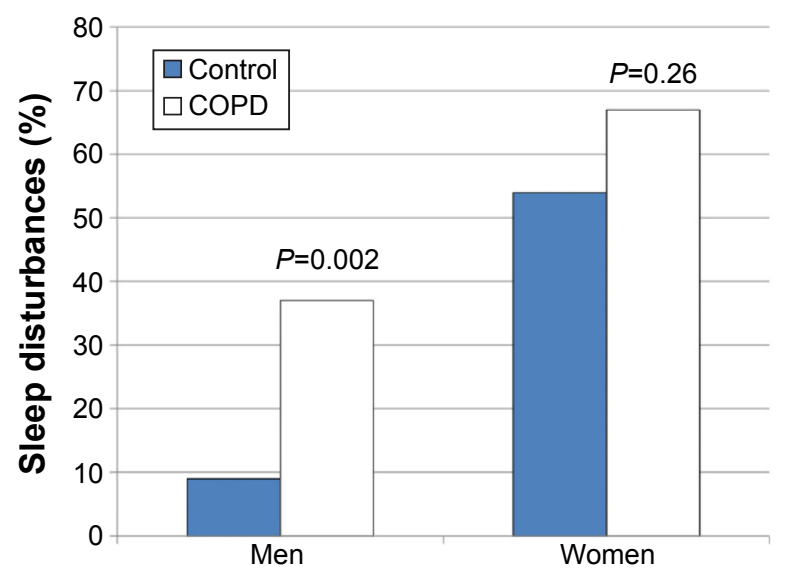

Figure 2 Reported sleep disturbances in men and women, with and without COPD. 
Table I Characteristics of the study population (mean \pm SD) or \%

\begin{tabular}{|c|c|c|c|c|c|c|}
\hline \multirow[t]{2}{*}{ Characteristics } & \multicolumn{3}{|l|}{ Men } & \multicolumn{3}{|l|}{ Women } \\
\hline & $\begin{array}{l}\text { No COPD } \\
(n=44)\end{array}$ & $\begin{array}{l}\text { COPD } \\
(n=49)\end{array}$ & $P$-value & $\begin{array}{l}\text { No COPD } \\
(n=46)\end{array}$ & $\begin{array}{l}\text { COPD } \\
(n=47)\end{array}$ & $P$-value \\
\hline Age (years) & $65 \pm 5.7$ & $66 \pm 6.0$ & 0.62 & $63 \pm 6.8$ & $64 \pm 6.0$ & 0.58 \\
\hline $\mathrm{BMI}\left(\mathrm{kg} / \mathrm{m}^{2}\right)$ & $28 \pm 4.4$ & $28 \pm 4.0$ & 0.61 & $28 \pm 4.8$ & $24 \pm 5.1$ & 0.0007 \\
\hline Smoking history & & & $<0.000$ I & & & $<0.000$ I \\
\hline Never smokers & 48 & 0 & & 47 & 0 & \\
\hline Ex-smokers & 45 & 68 & & 40 & 79 & \\
\hline Current smokers & 7 & 33 & & 13 & 21 & \\
\hline $\mathrm{FEV}_{1}$ (\% predicted) & $100 \pm 16$ & $55 \pm 18$ & $<0.000 \mathrm{I}$ & $108 \pm 16$ & $54 \pm 19$ & $<0.000$ I \\
\hline FVC (\% predicted) & $97 \pm 17$ & $81 \pm 16$ & $<\mathbf{0 . 0 0 0 I}$ & $1 \mid 3 \pm 17$ & $92 \pm 24$ & $<0.000$ I \\
\hline $\mathrm{SaO}_{\text {2awake }}(\%)$ & $95 \pm 1.4$ & $93 \pm 2.6$ & 0.0004 & $95 \pm 1.3$ & $93 \pm 2.0$ & $<\mathbf{0 . 0 0 0 I}$ \\
\hline $\mathrm{CRP}^{*} \mathrm{mg} / \mathrm{L}$ & $1.7(1.3-2.3)$ & $4.1(3.2-5.2)$ & $<0.000$ I & $1.9(1.3-2.9)$ & $2.3(1.7-3.1)$ & 0.52 \\
\hline IL-6* & $1.0(0.66-1.4)$ & $1.7(1.3-2.4)$ & 0.02 & $0.64(0.40-1.0)$ & $1.5(1.2-2.1)$ & 0.0007 \\
\hline MPO units & $324(274-383)$ & $264(224-312)$ & 0.08 & $218(149-318)$ & $319(256-398)$ & 0.06 \\
\hline BNP* & $78(58-106)$ & $99(73-133)$ & 0.28 & $79(63-100)$ & $110(84-144)$ & 0.07 \\
\hline Reported sleep disturbances & 9 & 37 & 0.002 & 55 & 67 & 0.25 \\
\hline Obstructive sleep apnea** & 49 & 51 & 0.75 & 59 & 41 & 0.047 \\
\hline Hypertension*** & 41 & 35 & 0.61 & 29 & 28 & 0.90 \\
\hline Ischemic heart disease $* * *$ & 14 & 23 & 0.25 & 2.4 & 12.8 & 0.07 \\
\hline Diabetes*** & 6.8 & 12 & 0.38 & 9.0 & 0 & 0.03 \\
\hline
\end{tabular}

Notes: *Geometric mean $(95 \% \mathrm{Cl})$; **AHI $\geq 10 / \mathrm{h}$; ***reported in questionnaire by the participant. Data in bold indicates variables with $P$-value $<0.05$ for between group comparison.

Abbreviations: $\mathrm{AHI}$, apnea-hypopnea index; $\mathrm{BMI}$, body mass index; $\mathrm{BNP}, \mathrm{B}$ natriuretic protein; $\mathrm{Cl}$, confidence interval; $\mathrm{CRP}$, $\mathrm{C}$-reactive protein; $\mathrm{FEV}$, forced expiratory volume in I second; FVC, forced vital capacity; IL-6, Interleukin-6; MPO, myeloperoxidase; $\mathrm{SaO}_{2 a w a k e}$, daytime oxygen saturation; SD, standard deviation.

more common among male patients with COPD compared with controls, whereas there were no differences in women (Figure 3).

Among controls, females had longer SL and a shorter TST when compared to males. When patients with COPD were compared to controls, men with COPD had significantly longer SL than the male control group whereas women with COPD had a longer TST, a larger proportion of the night spent in SWS and a lower AHI and ODI than women without COPD. Both men and women with COPD had significantly lower oxygen saturation $\left(\mathrm{SaO}_{2 \text { sleep }}\right)$ during the night compared with controls (Table 3 ). When adjusting for age, BMI, smoking history, and AHI, only the association between TST and COPD in women $(P<0.0001)$ and the association between SL and COPD in men $(P<0.0001)$ remained statically significant. The correlations between SL and also TST and anxiety/depression were assessed in the patient group with COPD, where information on HAD score had been obtained. There were no significant relationships either in men or women (data not shown). In addition, there were no significant relationship between either TST or SL and the SGRQ scores, either in men or women with COPD (data not shown).

In the male group of participants reporting sleep disturbances, there were no differences between patients with COPD and controls in any of the objective sleep measures

Table 2 Self-reported nighttime symptoms and use of hypnotics (\%)

\begin{tabular}{|c|c|c|c|c|c|c|}
\hline \multirow[t]{2}{*}{ Variables } & \multicolumn{3}{|l|}{ Men } & \multicolumn{3}{|l|}{ Women } \\
\hline & $\begin{array}{l}\text { No COPD } \\
(n=44)\end{array}$ & $\begin{array}{l}\text { COPD } \\
(n=49)\end{array}$ & $P$-value & $\begin{array}{l}\text { No COPD } \\
(n=46)\end{array}$ & $\begin{array}{l}\text { COPD } \\
(n=47)\end{array}$ & P-value \\
\hline Snoring & 59 & 65 & 0.59 & 76 & 65 & 0.24 \\
\hline Nocturnal reflux & 9.1 & 16 & 0.30 & 18 & 15 & $0.7 \mathrm{I}$ \\
\hline Nocturnal body movements & 14 & 35 & 0.02 & 44 & 37 & 0.47 \\
\hline Nocturia & 28 & 35 & 0.44 & 51 & 47 & 0.68 \\
\hline Difficulties initiating sleep & I I & 33 & 0.01 & 56 & 41 & 0.17 \\
\hline Difficulties maintaining sleep & 25 & 43 & 0.07 & 38 & 47 & 0.38 \\
\hline Early morning awakenings & 30 & 35 & 0.65 & 52 & 63 & 0.30 \\
\hline Symptoms of restless legs & II & 16 & 0.49 & 51 & 61 & 0.35 \\
\hline Use of hypnotics & 0 & 15 & 0.009 & 16 & 36 & 0.03 \\
\hline
\end{tabular}

Note: Data in bold indicates variables with $P$-value $<0.05$ for between group comparison. 


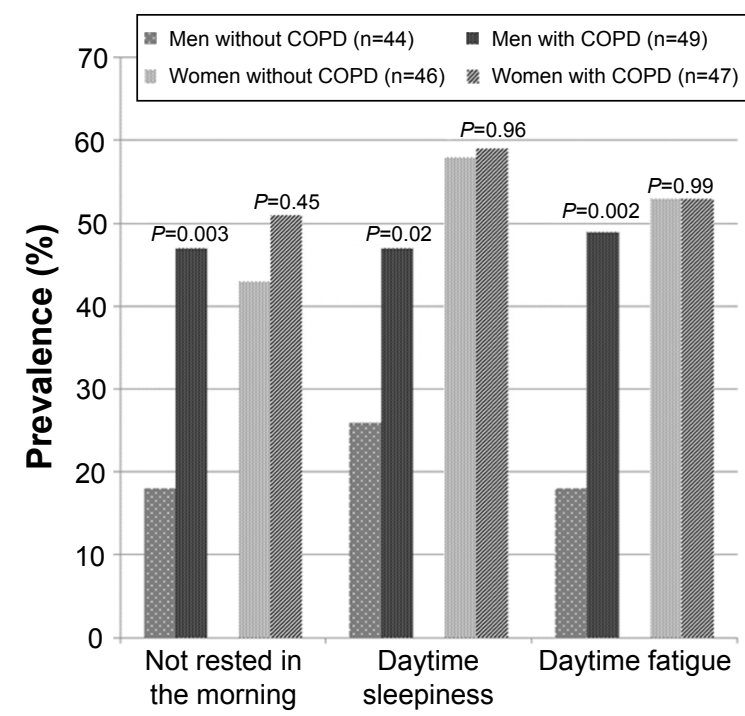

Figure 3 Reported daytime symptoms in men and women, with and without COPD.

whereas the women with concomitant COPD and sleep disturbances had longer TST than controls with sleep disturbances $(P=0.005)$, and this association remained significant when also adjusting for age, BMI, smoking history, and AHI $(P=0.004)$.

When further dividing the groups with COPD by reported sleep disturbances, male patients with COPD along with sleep disturbances had lower FVC, higher CRP, and MPO and a higher prevalence of chronic bronchitis and ischemic heart disease compared with controls. There were no statistically significant differences in clinical characteristics between patients with COPD along with and without reported sleep disturbances in women (Table 4). The differences for FVC $(P=0.01)$, CRP $(P=0.045)$, MPO $(P=0.047)$, chronic bronchitis $(P=0.003)$, and ischemic heart disease $(P=0.039)$ in men all remained significant when adjusting for age, BMI, smoking history, and AHI. In addition, adjusting also for HAD status did not significantly change the results (data not shown).

The association between health-related quality of life and reported sleep disturbances is presented in Figure 4. In men, sleep disturbances were associated with lower quality of life while no such significant association was found in women (Figure 4).

\section{Discussion}

The main finding of the present study is that despite an overall higher prevalence of sleep disturbances in women, the association between COPD and impaired sleep was more obvious in men. The association was also strengthened by recorded longer SL in men with COPD compared to men without COPD.

Sleep disturbances and daytime symptoms were significantly related to COPD in men, and both male and female patients with COPD more often used hypnotics, compared with controls, results seen also in earlier studies. ${ }^{2,9}$ It is known that women in general use more hypnotics than men and also in the present study the use of hypnotics among women was high; however there are, to our knowledge, no studies on sex differences in patients with COPD regarding the use of hypnotics. Male patients with COPD had more nighttime symptoms compared with controls, whereas there was no significant difference in women. Male patients with COPD along with sleep disturbances also had more impact on quality of life. Sleep disturbances in patients with COPD are common and has been reported in several earlier studies. Klink and Quan have reported that 39\% of patients with COPD along with nocturnal cough or wheezing indicate having difficulty initiating or maintaining sleep and that $29 \%$ of the patients reported daytime sleepiness. ${ }^{5}$ In addition, Geiger-Brown et al have shown associations between sleep quality and quality

Table 3 Results from the polysomnography recordings (mean \pm SD) and \%

\begin{tabular}{|c|c|c|c|c|c|c|}
\hline \multirow[t]{2}{*}{ Variables } & \multicolumn{3}{|l|}{ Men } & \multicolumn{3}{|l|}{ Women } \\
\hline & $\begin{array}{l}\text { No COPD } \\
(n=44)\end{array}$ & $\begin{array}{l}\text { COPD } \\
(n=49)\end{array}$ & $P$-value & $\begin{array}{l}\text { No COPD } \\
(n=46)\end{array}$ & $\begin{array}{l}\text { COPD } \\
(n=47)\end{array}$ & $P$-value \\
\hline TST (minutes) & $408 \pm 62$ & $395 \pm 82$ & 0.40 & $361 \pm 89$ & $43 I \pm 87$ & 0.0003 \\
\hline SL* (minutes) & $9.3(6.7-13)$ & $23(|7-3|)$ & $<0.0001$ & $20(14-28)$ & $15(\mid 1-19)$ & 0.21 \\
\hline Awakenings (number) & $\mathrm{II} \pm 4.6$ & $12 \pm 6.4$ & 0.21 & $10 \pm 4.3$ & $12 \pm 6.1$ & 0.07 \\
\hline Stage I-2 (\%) & $79 \pm 8.3$ & $82 \pm 8.4$ & 0.08 & $77 \pm 8.2$ & $72 \pm 9.2$ & 0.01 \\
\hline Stage 3 (\%) & $10 \pm 7.0$ & $7.7 \pm 6.0$ & 0.07 & $10 \pm 6.4$ & $14 \pm 8.0$ & 0.007 \\
\hline REM (\%) & $\mathrm{II} \pm 5.4$ & $10 \pm 5.5$ & 0.60 & $13 \pm 5.9$ & $13 \pm 5.9$ & 0.76 \\
\hline $\mathrm{AHI} *$ & $10(7.4-15)$ & $9.5(7.1-13)$ & 0.66 & I $3(9.6-18)$ & $8.6(6.6-I I)$ & 0.04 \\
\hline ODI* & $8.9(6.1-13)$ & $7.4(5.4-10)$ & 0.74 & II (8.|-|5) & $5.5(4.0-7.6)$ & 0.02 \\
\hline $\mathrm{SaO}_{2 \text { sleep }}$ & $94 \pm 1.6$ & $92 \pm 2.7$ & 0.0001 & $95 \pm 1.5$ & $92 \pm 2.0$ & $<0.0001$ \\
\hline
\end{tabular}

Notes: *Geometric mean $(95 \% \mathrm{Cl})$. Data in bold indicates variables with $P$-value $<0.05$ for between group comparison.

Abbreviations: $\mathrm{AHI}$, apnea-hypopnea index; $\mathrm{Cl}$, confidence interval; ODI, oxygen desaturation index; $\mathrm{REM}$, rapid eye movement; SaO ${ }_{2 \text { sleep }}$, significantly lower oxygen saturation during the night; SD, standard deviation SL, sleep latency; TST, total sleep time. 
Table 4 Characteristics of patients with COPD without and with sleep disturbances (mean \pm SD) or \%

\begin{tabular}{|c|c|c|c|c|c|c|}
\hline \multirow[t]{2}{*}{ Characteristics } & \multicolumn{3}{|l|}{ Men } & \multicolumn{3}{|l|}{ Women } \\
\hline & $\begin{array}{l}\text { No sleep disturbance } \\
(n=31)\end{array}$ & $\begin{array}{l}\text { Sleep disturbance } \\
(n=18)\end{array}$ & $P$-value & $\begin{array}{l}\text { No sleep disturbance } \\
(n=15)\end{array}$ & $\begin{array}{l}\text { Sleep disturbance } \\
(n=30)\end{array}$ & $P$-value \\
\hline Age (years) & $67 \pm 6.4$ & $63 \pm 4.6$ & 0.051 & $65 \pm 5.7$ & $64 \pm 6.2$ & 0.36 \\
\hline BMI $\left(\mathrm{kg} / \mathrm{m}^{2}\right)$ & $27 \pm 4.4$ & $29 \pm 3.3$ & 0.26 & $24 \pm 4.2$ & $25 \pm 5.7$ & 0.87 \\
\hline $\mathrm{FEV}_{1} \%$ predicted & $58 \pm 17$ & $51 \pm 19$ & 0.21 & $51 \pm 20$ & $55 \pm 20$ & 0.54 \\
\hline FVC \% predicted & $85 \pm 16$ & $73 \pm 15$ & 0.01 & $86 \pm 27$ & $94 \pm 23$ & 0.29 \\
\hline $\mathrm{SaO}_{\text {2awake }}$ & $93 \pm 2.8$ & $93 \pm 2.5$ & $0.7 \mathrm{I}$ & $93 \pm 1.7$ & $93 \pm 2.1$ & 0.75 \\
\hline CRP* & $3.3(2.5-4.3)$ & $5.9(3.6-9.7)$ & 0.03 & $2.0(I .1-3.6)$ & $2.5(1.7-3.7)$ & 0.45 \\
\hline IL-6* & $1.6(I . I-2.4)$ & $2.0(1.1-3.8)$ & 0.48 & $1.6(0.92-2.9)$ & $1.4(1.0-2.0)$ & 0.64 \\
\hline MPO & $224(182-277)$ & $357(283-450)$ & 0.006 & $263(166-416)$ & $363(277-474)$ & 0.18 \\
\hline BNP* & $10 \mid(69-151)$ & $93(55-157)$ & $0.7 \mathrm{I}$ & $103(58-181)$ & II 6 (84-159) & 0.67 \\
\hline Ischemic heart disease $\mathrm{e}^{* *}$ & 13 & 41 & 0.03 & 13 & 13 & 0.99 \\
\hline Chronic bronchitis & 21 & 76 & $<0.000$ I & 40 & 47 & 0.67 \\
\hline
\end{tabular}

Notes: *Geometric mean $(95 \% \mathrm{Cl})$; **reported in questionnaire by the participant. Data in bold indicates variables with $P$-value $<0.05$ for between group comparison. Abbreviations: BMI, body mass index; BNP, B natriuretic protein; $\mathrm{Cl}$, confidence interval; CRP, C-reactive protein; FEV , forced expiratory volume in I second; FVC, forced vital capacity; IL-6, interleukin-6; MPO, myeloperoxidase; $\mathrm{SaO}_{2 \text { awake }}$, daytime oxygen saturation; SD, standard deviation.

of life, where the quality of life scores were worse in poor sleepers compared with good sleepers. ${ }^{31}$ However, to our knowledge, there are no earlier studies investigating sex differences as the present study does.

Sleep in patients with COPD has been shown as fragmented, with diminished amounts of SWS and REM sleep. ${ }^{12}$ McSharry et al showed that in a patient with COPD, cohort sleep efficiency was $66 \% \pm 17 \%$ and there was also an altered sleep architecture with diminished periods of REM sleep. ${ }^{12}$
The same study also showed that the daytime $\mathrm{PaO}_{2}$ (partial pressure of oxygen in the blood) correlated independently with sleep efficiency, whereas $F E V_{1}$ positively correlated with sleep fragmentation..$^{12}$ In the present study, men with COPD had significantly longer SL, and there was a trend for an association between diminished amounts of SWS and COPD in men. It was also primarily men who reported sleep disturbances whereas women with COPD had longer TST and also more SWS compared with controls. However, although having

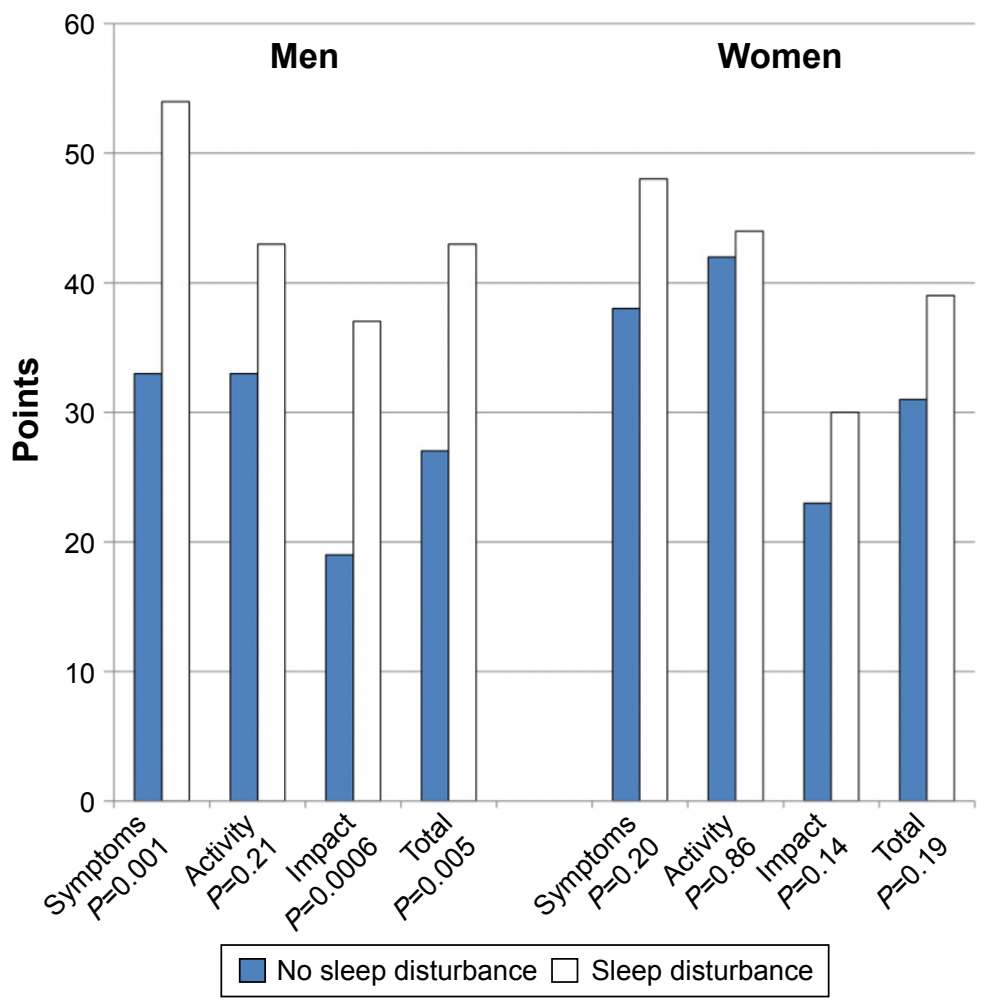

Figure 4 Health-related quality of life, measured with St George Respiratory Questionnaire, in men and women with COPD who do not report or do report having sleep disturbances. 
longer TST and more SWS, both patients with COPD and controls in the female group had normal to low values compared with reported numbers in a general population. ${ }^{32,33}$

In this study, men with COPD reported more nighttime symptoms, such as nocturnal body movements, DIS, DMS, and also more problems with sleep disturbances compared with controls. The COPD has previously been associated with daytime sleepiness and poor quality of sleep ${ }^{34}$ and a large twin study in men showed that pulmonary disease was correlated with sleeping problems such as trouble falling asleep, staying asleep, waking often, and being tired when awake. ${ }^{35}$ A case-control study in 52 patients with mild-to-moderate COPD and 52 controls showed patients with COPD to have less sleep efficiency, shorter TST, and lower mean nighttime oxygen saturation compared to controls. The patients with COPD were also significantly more likely to report symptoms such as difficulty in initiating and maintaining sleep compared with controls. ${ }^{36}$ However, there were no sex stratifications in that study. ${ }^{36}$

The present study show increased levels of IL-6 in patients with COPD of both sexes and increased CRP in men with COPD compared with controls. Male patients with COPD along with sleep disturbances also had higher levels of both CRP and MPO after controlling for confounders. The association between sleep disturbances, COPD, and systemic inflammation has been poorly investigated although there are studies showing increased systemic inflammation in COPD ${ }^{37}$ and also studies showing increased systemic inflammation in subjects with sleep disturbances and sleep restriction. ${ }^{38}$ In addition, results from population studies have indicated stronger associations between systemic inflammation and sleep in men than in women. ${ }^{39,40}$ Furthermore, in a study of 53 patients with COPD, men with higher CRP values were associated with larger decline in $\mathrm{FEV}_{1}$ compared to women. ${ }^{41}$ This could imply that increased inflammatory burden in men might worsen their sleep pattern and subsequently increase their sleep-related symptoms and disturbances although more studies in this field are needed.

This study was conducted in a sex-mixed cohort of patients with COPD and controls with larger groups than compared with earlier studies on sleep in COPD and good generalizability. Nonetheless, there are considerations when interpreting the results. First, all case-control studies may be subjected to selection bias. Second, this was a cross-sectional study and therefore we cannot conclude causality. Third, information on anxiety and depression and also health-related quality of life was only collected in the patient group and not in the controls. Therefore, we could not fully assess the impact these may have on our results. However, there was no correlation between objectively measured sleep and anxiety or depression in the COPD group where HAD score was measured. In addition, adjusting the analysis for subjective sleep disturbances for HAD score in the COPD group did not significantly change the results. Furthermore, there was no correlation between objectively measured sleep and health-related quality of life (SGRQ score) in the COPD group. Fourth, there was no question on napping during the day, a variable which may have an impact on both nighttime sleep and daytime function. Finally, the use of a cutoff of 4 hours for adequate polysomnography could be argued to be too short and that it is possible that those with subjectively worse sleep tolerate recording equipment less well, and therefore, have shorter total recording time. We tested the hypothesis that those with subjectively worse sleep ("having sleep disturbances") would have shorter total recording time compared with those without sleep disturbances. However, this relationship was not significant either in the whole group, in men or in women. In addition, the relationship was not significant either in the patients with COPD or in controls.

\section{Conclusion}

In this study, women had a higher overall prevalence of sleep disturbances and in controls longer SL and shorter TST. However, men with COPD reported more sleep disturbances compared with controls, and it was also more common in this group to report both daytime and nighttime symptoms. Both male and especially female patients with COPD indicated a high use of hypnotics whereas females both as a whole and in the COPD group showed better polysomnography data with longer TST than controls. In the group of male patients with COPD along with sleep disturbances higher CRP and MPO was seen and men with COPD also indicated lower quality of life. Therefore, we conclude that the associations between COPD and impaired sleep were clearer in men than in women and the association between reported impaired quality of sleep was also confirmed by recorded longer SL in men with COPD compared to men without COPD.

\section{Acknowledgments}

The study was financially supported by the Swedish Heart and Lung Foundation and the Swedish Association against Heart and Lung Diseases. Preliminary results from the study were presented as an abstract at the American Thoracic Society 2010 International Conference, May 14-19, 2010; New Orleans, LA, USA. 


\section{Author contributions}

JTH contributed to data collection, data analysis, and manuscript preparation. ISÓ contributed to study design, data analysis, and manuscript preparation. BB, TG, and EL contributed to study design and review of the manuscript. CJ contributed to study design, data collection, data analysis, and manuscript preparation. JTH, ISÓ, and CJ had full access to all the data in the study and were responsible for the integrity of the data and the accuracy of the data analysis. All authors contributed toward data analysis, drafting and critically revising the paper, gave final approval of the version to be published, and agree to be accountable for all aspects of the work.

\section{Disclosure}

The authors report no conflicts of interest in this work.

\section{References}

1. Price D, Small M, Milligan G, Higgins V, Gil EG, Estruch J. Impact of night-time symptoms in COPD: a real-world study in five European countries. Int J Chron Obstruct Pulmon Dis. 2013;8:595-603.

2. Cormick W, Olson LG, Hensley MJ, Saunders NA. Nocturnal hypoxaemia and quality of sleep in patients with chronic obstructive lung disease. Thorax. 1986;41(11):846-854.

3. Rennard S, Decramer M, Calverley PM, et al. Impact of COPD in North America and Europe in 2000: subjects' perspective of Confronting COPD International Survey. Eur Respir J. 2002;20(4):799-805.

4. Agusti A, Hedner J, Marin JM, Barbe F, Cazzola M, Rennard S. Nighttime symptoms: a forgotten dimension of COPD. Eur Respir Rev. 2011;20(121):183-194.

5. Klink M, Quan SF. Prevalence of reported sleep disturbances in a general adult population and their relationship to obstructive airways diseases. Chest. 1987;91(4):540-546.

6. Jones PW. Health status measurement in chronic obstructive pulmonary disease. Thorax. 2001;56(11):880-887.

7. Benediktsdottir B, Janson C, Lindberg E, et al. Prevalence of restless legs syndrome among adults in Iceland and Sweden: lung function, comorbidity, ferritin, biomarkers and quality of life. Sleep Med.2010;11(10): 1043-1048.

8. Lange P, Marott JL, Vestbo J, Nordestgaard BG. Prevalence of nighttime dyspnoea in COPD and its implications for prognosis. Eur Respir $J$ 2014;43(6):1590-1598.

9. McNicholas WT, Verbraecken J, Marin JM. Sleep disorders in COPD: the forgotten dimension. Eur Respir Rev. 2013;22(129):365-375.

10. Catterall JR, Calverley PM, MacNee W, et al. Mechanism of transient nocturnal hypoxemia in hypoxic chronic bronchitis and emphysema. J Appl Physiol (1985). 1985;59(6):1698-1703.

11. Marrone O, Salvaggio A, Insalaco G. Respiratory disorders during sleep in chronic obstructive pulmonary disease. Int J Chron Obstruct Pulmon Dis. 2006;1(4):363-372.

12. McSharry DG, Ryan S, Calverley P, Edwards JC, McNicholas WT Sleep quality in chronic obstructive pulmonary disease. Respirology. 2012;17(7):1119-1124.

13. Fleetham J, West P, Mezon B, Conway W, Roth T, Kryger M. Sleep, arousals, and oxygen desaturation in chronic obstructive pulmonary disease. The effect of oxygen therapy. Am Rev Respir Dis. 1982;126(3): 429-433.

14. Mallampalli MP, Carter CL. Exploring sex and gender differences in sleep health: a society for women's health research report. $J$ Womens Health (Larchmt). 2014;23(7):553-562.
15. Theorell-Haglow J, Berne C, Janson C, Lindberg E. Obstructive sleep apnoea is associated with decreased insulin sensitivity in females. Eur Respir J. 2008;31(5):1054-1060.

16. Lindberg E, Janson C, Gislason T, Svardsudd K, Hetta J, Boman G. Snoring and hypertension: a 10 year follow-up. Eur Respir J. 1998;11(4): 884-889.

17. Lindberg E, Janson C, Svardsudd K, Gislason T, Hetta J, Boman G. Increased mortality among sleepy snorers: a prospective population based study. Thorax. 1998;53(8):631-637.

18. Janson C, Lindberg E, Gislason T, Elmasry A, Boman G. Insomnia in mena 10-year prospective poulation based study. Sleep. 2001;24(4):425-430.

19. Walters AS. Toward a better definition of the restless legs syndrome. The International Restless Legs Syndrome Study Group. Mov Disord. 1995;10(5):634-642.

20. Janson C, Norbäck D, Omenaas E, et al. Insomnia is more common among subjects living in damp buildings. Occup Environ Med. 2005;62: $113-118$.

21. Jones PW, Quirk FH, Baveystock CM, Littlejohns P. A self-complete measure of health status for chronic airflow limitation. The St George's Respiratory Questionnaire. Am Rev Respir Dis. 1992;145(6):1321-1327.

22. Zigmond AS, Snaith RP. The hospital anxiety and depression scale. Acta Psychiatr Scand. 1983;67(6):361-370.

23. Janson C, Björnsson E, Hetta J, Boman G. Anxiety and depression in relation to respiratory symptoms and asthma. Am J Respir Crit Care Med. 1994;149:930-934.

24. Lewin B, Robertson IH, Cay EL, Irving JB, Campbell M. Effects of self-help post-myocardial-infarction rehabilitation on psychological ajustment and use of health services. Lancet. 1995;339:1036-1040.

25. Dahlén I, Janson C. Anxiety and depression are related to the outcom of emergency treatment in patients with obstructive pulmonary disease. Chest. 2002;122(5):1633-1637.

26. Burney PG, Luczynska C, Chinn S, Jarvis D. The European Community Respiratory Health Survey. Eur Respir J. 1994;7(5):954-960.

27. Bestall JC, Paul EA, Garrod R, Garnham R, Jones PW, Wedzicha JA Usefulness of the Medical Research Council (MRC) dyspnoea scale as a measure of disability in patients with chronic obstructive pulmonary disease. Thorax. 1999;54(7):581-586.

28. Svensson M, Lindberg E, Naessen T, Janson C. Risk factors associated with snoring in women with special emphasis on body mass index: a population-based study. Chest. 2006;129(4):933-941.

29. Standardized lung function testing. Report working party. Bull Eur Physiopathol Respir. 1983;19 Suppl 5:1-95.

30. Rechtschaffen A, Kales A. A Manual of Standardized Terminology, Techniques, and Scoring System for Sleep Stages in Human Subjects. Washington, DC: US National Public Health Service, US Government Printing Office; 1968.

31. Geiger-Brown J, Lindberg S, Krachman S, et al. Self-reported sleep quality and acute exacerbations of chronic obstructive pulmonary disease. Int J Chron Obstruct Pulmon Dis. 2015;10:389-397.

32. Sahlin C, Franklin KA, Stenlund H, Lindberg E. Sleep in women: normal values for sleep stages and position and the effect of age, obesity, sleep apnea, smoking, alcohol and hypertension. Sleep Med. 2009; 10(9): 1025-1030.

33. Redline S, Kirchner HL, Quan SF, Gottlieb DJ, Kapur V, Newman A. The effects of age, sex, ethnicity, and sleep-disordered breathing on sleep architecture. Arch Intern Med. 2004;164(4):406-418.

34. Ali Zohal M, Yazdi Z, Kazemifar AM. Daytime sleepiness and quality of sleep in patients with COPD compared to control group. Glob $J$ Health Sci. 2013;5(3):150-155.

35. Fabsitz RR, Sholinsky P, Goldberg J. Correlates of sleep problems among men: the Vietnam Era Twin Registry. J Sleep Res. 1997;6(1):50-56.

36. Valipour A, Lavie P, Lothaller H, Mikulic I, Burghuber OC. Sleep profile and symptoms of sleep disorders in patients with stable mild to moderate chronic obstructive pulmonary disease. Sleep Med. 2011; 12(4):367-372.

37. Evans RA, Morgan MD. The systemic nature of chronic lung disease. Clin Chest Med. 2014;35(2):283-293. 
38. Faraut B, Boudjeltia KZ, Vanhamme L, Kerkhofs M. Immune, inflammatory and cardiovascular consequences of sleep restriction and recovery. Sleep Med Rev. 2012;16(2):137-149.

39. Olafsdottir IS, Gislason T, Gudnason V, et al. CRP is associated with lung function decline in men but not women: a prospective study. Respir Med. 2013;107(1):91-97.
40. Thorleifsson SJ, Margretardottir OB, Gudmundsson G, et al. Chronic airflow obstruction and markers of systemic inflammation: results from the BOLD study in Iceland. Respir Med. 2009;103(10):1548-1553.

41. Olafsdottir IS, Gislason T, Thjodleifsson B, et al. Gender differences in the association between C-reactive protein, lung function impairment, and COPD. Int J Chron Obstruct Pulmon Dis. 2007;2(4):635-642.

\section{Publish your work in this journal}

The International Journal of COPD is an international, peer-reviewed journal of therapeutics and pharmacology focusing on concise rapid reporting of clinical studies and reviews in COPD. Special focus is given to the pathophysiological processes underlying the disease, intervention programs, patient focused education, and self management protocols.

\section{Dovepress}

This journal is indexed on PubMed Central, MedLine and CAS. The manuscript management system is completely online and includes a very quick and fair peer-review system, which is all easy to use. Visit $\mathrm{http}: / / \mathrm{www}$. dovepress.com/testimonials.php to read real quotes from published authors.

\footnotetext{
Submit your manuscript here: http://www.dovepress.com/international-journal-of-chronic-obstructive-pulmonary-disease-journal
} 